\title{
Erratum to: Experimental Determination of Third Derivative of the Gibbs Free Energy, $G$ II: Differential Pressure Perturbation Calorimetry
}

\author{
Yoshikata Koga • Peter Westh • Akira Inaba • \\ Kalyan Sou $\cdot$ Ken-ichi Tozaki
}

Published online: 24 March 2010

(C) Springer Science+Business Media, LLC 2010

\section{Erratum to: J Solution Chem (2010) 39: 431-440 DOI 10.1007/s10953-010-9510-4}

In an attempt at refining the methodology described in this article, we came to realize recently that there are inadvertent errors in Eq. 7 and Eq. 8. The right hand side of Eq. 7 should have an extra term $-\Delta V$ and that of Eq. $8+(\Delta V / V)$. Namely, Eq. 7 and Eq. 8 should read:

$$
\begin{aligned}
& -\Delta(\delta H / \delta p)=V T \Delta \alpha_{p}+\Delta V T \alpha_{p}-\Delta V, \\
& T \Delta \alpha_{p}=\Delta^{S V} \delta=-\frac{1}{V}\left(\frac{\Delta \delta H}{\delta p}\right)-\frac{\Delta V}{V} T \alpha_{p}+(\Delta V / V) .
\end{aligned}
$$

Since we determined the apparatus constant including this error by using sample pairs with known $\Delta \alpha_{p}$, the final results shown in Fig. 5 suffer little effect. Thus, our conclusion that the basic concept of the project is feasible remains valid.

We also came to realize that the "effective" volumes of the two sample cells could be another issue. Namely, the sample volumes must be such that are actually "felt" by the

The online version of the original article can be found under doi:10.1007/s10953-010-9510-4.

Y. Koga $(\bowtie)$

Department of Chemistry, The University of British Columbia, Vancouver, BC, Canada V6T 1Z1

e-mail:koga@chem.ubc.ca

P. Westh

NSM Research Unit for Functional Biomaterials, Roskilde University, Roskilde 4000, Denmark

A. Inaba

Research Center for Structural Thermodynamics, Osaka University, Toyonaka, Osaka 560-0043, Japan

K. Sou $\cdot$ K. Tozaki

Department of Physics, Faculty of Education, Chiba University, Chiba 263-8522, Japan 
thermo-module, and may not be the same as determined gravimetrically. When our attempt at refining the present methodology taking these and other possible issues into account ends successfully, another manuscript will be submitted to this journal. 